\title{
Patients' and physicians' interpretation of chemotherapy-induced peripheral neurotoxicity
}

Citation for published version (APA):

Cavaletti, G., Cornblath, D. R., Merkies, I. S. J., Postma, T. J., Rossi, E., Alberti, P., Bruna, J., Argyriou, A. A., Briani, C., Velasco, R., Kalofonos, H. P., Psimaras, D., Ricard, D., Pace, A., Faber, C. G., Lalisang, R. I., Brandsma, D., Koeppen, S., Kerrigan, S., ... Cl-PeriNomS Grp (2019). Patients' and physicians' interpretation of chemotherapy-induced peripheral neurotoxicity. Journal of the Peripheral Nervous System, 24(1), 111-119. https://doi.org/10.1111/jns.12306

Document status and date:

Published: 01/03/2019

DOI:

10.1111/jns.12306

Document Version:

Publisher's PDF, also known as Version of record

Document license:

Taverne

Please check the document version of this publication:

- A submitted manuscript is the version of the article upon submission and before peer-review. There can be important differences between the submitted version and the official published version of record.

People interested in the research are advised to contact the author for the final version of the publication, or visit the DOI to the publisher's website.

- The final author version and the galley proof are versions of the publication after peer review.

- The final published version features the final layout of the paper including the volume, issue and page numbers.

Link to publication

\footnotetext{
General rights Owners
rights.

- You may freely distribute the URL identifying the publication in the public portal. please follow below link for the End User Agreement:

www.umlib.nl/taverne-license

Take down policy

If you believe that this document breaches copyright please contact us at:

repository@maastrichtuniversity.nl

providing details and we will investigate your claim.
}

Copyright and moral rights for the publications made accessible in the public portal are retained by the authors and/or other copyright owners and it is a condition of accessing publications that users recognise and abide by the legal requirements associated with these

- Users may download and print one copy of any publication from the public portal for the purpose of private study or research.

- You may not further distribute the material or use it for any profit-making activity or commercial gain

If the publication is distributed under the terms of Article $25 \mathrm{fa}$ of the Dutch Copyright Act, indicated by the "Taverne" license above, 


\title{
Patients' and physicians' interpretation of chemotherapy- induced peripheral neurotoxicity
}

\author{
Guido Cavaletti $^{1}$ ( ) | David R. Cornblath ${ }^{2}$ | Ingemar S.J. Merkies ${ }^{3,4}$ | Tjeerd J. Postma ${ }^{5}$ | \\ Emanela Rossi $^{6}$ | Paola Alberti ${ }^{1}$ ( ) | Jordi Bruna ${ }^{7}$ | Andreas A. Argyriou ${ }^{8}$ | \\ Chiara Briani $^{9}$ (1) | Roser Velasco ${ }^{7}$ | Haralabos P. Kalofonos ${ }^{8}$ | Dimitri Psimaras ${ }^{10}$ | \\ Damien Ricard ${ }^{11}$ | Andrea Pace ${ }^{12}$ | Catharina G. Faber ${ }^{3}$ | Roy I. Lalisang ${ }^{13}$ | \\ Dieta Brandsma ${ }^{14}$ | Susanne Koeppen ${ }^{15}$ | Simon Kerrigan ${ }^{16}$ | Angelo Schenone ${ }^{17,18}$ | \\ Wolfgang Grisold $^{19}$ | Anna Mazzeo ${ }^{20}$ | Luca Padua $^{21}$ | Susan G. Dorsey ${ }^{22}$ | \\ Marta Penas-Prado ${ }^{23}$ | Maria G. Valsecchi ${ }^{6}$ | the Cl-PeriNomS Group ${ }^{\dagger}$ \\ ${ }^{1}$ Experimental Neurology Unit, School of Medicine and Surgery, University of Milano-Bicocca, Monza, Italy \\ ${ }^{2}$ Department of Neurology, Johns Hopkins University School of Medicine, Baltimore, Maryland, USA \\ ${ }^{3}$ Department of Neurology, Spaarne Hospital, Hoofddorp/Maastricht University Medical Center, Maastricht, The Netherlands \\ ${ }^{4}$ Department of Neurology, St. Elisabeth Hospital, Willemstad, Curaçao \\ ${ }^{5}$ Department of Neurology, Amsterdam UMC, Vrije Universiteit Amsterdam, Amsterdam, The Netherlands \\ ${ }^{6}$ Center of Biostatistics for Clinical Epidemiology, School of Medicine and Surgery, University of Milano-Bicocca, Monza, Italy \\ ${ }^{7}$ Unit of Neuro-Oncology, Department of Neurology, University Hospital of Bellvitge-IDIBELL (Bellvitge Biomedical Research Institute), Hospitalet, Spain \\ ${ }^{8}$ Division of Clinical Oncology-Department of Medicine, University Hospital of Patras, Patras, Greece \\ ${ }^{9}$ Department of Neurosciences, University of Padova, Padova, Italy \\ ${ }^{10}$ Hôpital de la Pitié-Salpêtrière, AP-HP, Service de Neurologie Mazarin, Paris, France \\ ${ }^{11}$ Service de Neurologie de I'HIE Percy, Service de Santé des Armées, Clamart, France \\ ${ }^{12}$ Neuroncology Unit, IRCCS Regina Elena National Cancer Institute, Rome, Italy \\ ${ }^{13}$ Division of Medical Oncology, Department of Internal Medicine, GROW-School of Oncology and Developmental Biology, Maastricht University Medical Center, \\ Maastricht, The Netherlands \\ ${ }^{14}$ Department of Neuro-oncology, Netherlands Cancer Institute, Amsterdam, The Netherlands \\ ${ }^{15}$ Department of Neurology and West German Cancer Center, University of Essen, Essen, Germany \\ ${ }^{16}$ Edinburgh Centre for Neuro-Oncology and Edinburgh Cancer Research Centre, Western General Hospital, Edinburgh, UK \\ ${ }^{17}$ Department of Neurosciences, Rehabilitation, Ophthalmology, Genetic and Maternal Infantile Sciences, University of Genova and Ospedale Policlinico San Martino, \\ Genoa, Italy \\ ${ }^{18}$ Dipartimento di Neuroscienze, IRCCS Ospedale Policlinico San Martino, Genoa, Italy \\ ${ }^{19}$ Ludwig Boltzmann Institute for Experimental and Clinical Traumatology, Vienna, Austria \\ ${ }^{20}$ Department of Clinical and Experimental Medicine, University of Messina, Messina, Italy \\ ${ }^{21}$ Department of Neurosciences Cattolica University, Rome and IRCCS Don Carlo Gnocchi, Milan, Italy \\ ${ }^{22}$ Department of Pain \& Translational Symptom Science, University of Maryland School of Nursing and the Marlene and Stewart Greenebaum Cancer Center, \\ Baltimore, Maryland, USA \\ ${ }^{23}$ Department of Neuro-Oncology, The UT MD Anderson Cancer Center, Houston, Texas, USA
}

\section{Correspondence}

Prof. Guido Cavaletti, Experimental Neurology

Unit, School of Medicine and Surgery,

University Milano, Bicocca, v. Cadore
To test if and how chemotherapy-induced peripheral neurotoxicity (CIPN) is perceived differently by patients and physicians, making assessment and interpretation challenging. We performed a secondary analysis of the $\mathrm{Cl}$-PeriNomS study which included 281 patients with stable

\footnotetext{
The members of $\mathrm{Cl}$-PeriNomS Group are presented in Appendix.
} 
48, I-20900, Monza, Italy. Email: guido.cavaletti@unimib.it
CIPN. We tested: (a) the association between patients' perception of activity limitation in performing eight common tasks and neurological impairment and (b) how the responses to questions related to these daily activities are interpreted by the treating oncologist. To achieve this, we compared patients' perception of their activity limitation with neurological assessment and the oncologists' blind interpretation. Distribution of the scores attributed by oncologists to each daily life maximum limitation ("impossible") generated three groups: Group 1 included limitations oncologists attributed mainly to motor impairment; Group 2 ones mainly attributed to sensory impairment and Group 3 ones with uncertain motor and sensory impairment. Only a subset of questions showed a significant trend between severity in subjective limitation, reported by patients, and neurological impairment. In Group 1, neurological examination confirmed motor impairment in only $51 \%-65 \%$ of patients; $76 \%-78 \%$ of them also had vibration perception impairment. In Group 2, sensory impairment ranged from $84 \%$ to $100 \%$; some degree of motor impairment occurred in 43\%-56\% of them. In Group 3 strength reduction was observed in 49\%$50 \%$ and sensory perception was altered in up to $82 \%$. Interpretation provided by the panel of experienced oncologists was inconsistent with the neurological impairment. These observations highlight the need of a core set of outcome measures for future CIPN trials.

\section{KEYWORDS}

assessment, chemotherapy, neurotoxicity, patient reported outcome measures, side effects

\section{1 | INTRODUCTION}

In chemotherapy-induced peripheral neurotoxicity (CIPN) stockingand-glove numbness, paresthesias and sensory ataxia are predominant, but motor involvement can also occur after anti-tubulin drugs and "targeted" agents treatment. ${ }^{1,2}$

CIPN recognition and monitoring are crucial in clinical practice since improper assessment can delay treatment plan modification, at the moment the only effective way to limit CIPN severity, and cause more severe and long-term impairment. However, CIPN is perceived differently by patients and health care providers, ${ }^{3}$ and sometimes under-reported by patients. ${ }^{4}$

CIPN assessment is a critical issue also in the design and interpretation of neuroprotection clinical trials. ${ }^{5}$ The earliest clinical trials relied on the US National Cancer Institute-Common Toxicity Criteria for Adverse Events (NCI-CTC AE) scale to grade CIPN severity, but evidence suggests it is not the optimal endpoint. ${ }^{6}$

Therefore, different assessment tools have been developed, such as the Total Neuropathy Score (TNS), and self-administered questionnaires, particularly the European Organization for Research and Treatment in Cancer (EORTC) QLQ-CIPN2O and the Functional Assessment of Cancer Therapy/Gynaecologic Oncology GroupNeurotoxicity (FACT-GOG Ntx). ${ }^{7,8}$

According to Regulatory Agencies, these Patient Reported Outcome (PRO) measures may represent a robust primary endpoint (https://www.fda.gov/downloads/drugs/guidances/ ucm193282.pdf). However, concerns have been raised on their capacity to capture all CIPN clinical features. ${ }^{9,10}$

Moreover, simple questions related to daily living activities can effectively reflect personal impairment, but these limitations might be ascribed to different conditions besides CIPN: weakness due to severe anemia, cancer-related fatigue, chemotherapy-induced cognitive impairment ("chemofog"), cancer-related pain and psychosomatic disorders. ${ }^{11}$

To address these issues, we performed a secondary analysis of the $\mathrm{Cl}$-PeriNomS study dataset to test the association between patients' perception of activity limitation and actual neurological impairment and how patient responses are interpreted by the treating oncologist.

\section{2 | PATIENTS AND METHODS}

The $\mathrm{Cl}$-PeriNoms database, which included 281 patients with stable CIPN and no other cause of motor or sensory impairment, was used as the reference population for the survey. In that study, each patient was neurologically examined and at each visit the neurological status was evaluated according to the clinical version of the Total Neuropathy Score-clinical (TNSc) as previously described. ${ }^{12}$ Two neurologists experienced in assessing CIPN (G.C., P.A.) selected, among the list of questions submitted to each patient participating to the Cl-PeriNoms study, 8 tasks scored as "impossible to be performed" by at least $5 \%$ of the patients (Table 1). An electronic form that enabled assessment for each of the 8 tasks, to grade separately expected motor or sensory impairment from 0 (no impairment) to 10 (maximum severity), in a hypothetical patient unable to perform the task, was mailed to oncologists working at centers participating to the $\mathrm{Cl}$-PeriNoms study. A total of 44 oncologists completed the survey form and their responses were used for classifying the tasks as able or not to detect motor or sensory impairment.

In order to test the criterion validity of each self-report limitation, we have analyzed data according to the presence (frequency) of CIPN, 
TABLE 1 Results of the oncologists scoring on selected questions according to motor or sensory impairment ( $P$-values on the null hypothesis of median indecision score of 5)

\begin{tabular}{|c|c|c|c|c|c|c|}
\hline & \multicolumn{3}{|l|}{ Motor } & \multicolumn{3}{|l|}{ Sensory } \\
\hline & Median & IQR & $P$-value & Median & IQR & $P$-value \\
\hline \multicolumn{7}{|c|}{ Group 1-limitations attributed mainly to motor impairment } \\
\hline Walking up two flights of stairs & 7.0 & $(6.0-8.5)$ & $<0.0001$ & 3.0 & $(2.0-4.5)$ & $<0.0001$ \\
\hline \multicolumn{7}{|c|}{ Group 2-limitations attributed mainly to sensory impairment } \\
\hline Handle small objects & 2.0 & $(0.0-3.0)$ & $<0.0001$ & 8.0 & $(6.5-9.5)$ & $<0.0001$ \\
\hline Zip your trousers & 1.0 & $(0.5-4.0)$ & 0.0003 & 8.0 & $(6.0-9.0)$ & $<0.0001$ \\
\hline Tie your laces & 1.0 & $(0.0-4.0)$ & $<0.0001$ & 8.0 & $(6.0-9.0)$ & $<0.0001$ \\
\hline \multicolumn{7}{|c|}{ Group 3-limitations attributed both to motor and sensory impairment } \\
\hline Stand on one leg & 5.0 & $(2.0-8.0)$ & 0.5114 & 4.0 & $(1.5-6.0)$ & 0.1325 \\
\hline Walk on uneven ground & 5.0 & $(2.0-7.0)$ & 1.0000 & 6.0 & $(4.0-7.0)$ & 0.2682 \\
\hline
\end{tabular}

Abbreviation: IQR, interquartile range.

without taking into account its severity. Comparisons were performed between the oncologists' responses and the scores obtained in strength and vibration detection threshold using the TNSc criteria. Oncologists' interpretation of patients' answers was blind to the neurological assessment.

\section{3 | STANDARD PROTOCOL APPROVALS, REGULATIONS AND PATIENT CONSENTS}

The original $\mathrm{Cl}$-PeriNoms study protocol ${ }^{12}$ was examined and approved by the IRB/EC of each participating center; written informed consent was obtained from all participants. The study was conducted in accordance with the guidelines of the declaration of Helsinki (amendment October 2000, Edinburgh), and applicable local regulatory requirements and laws.

\section{4 | DATA AVAILABILITY STATEMENT}

Any data not published within the article will be shared, in an anonymized form, by request from any qualified investigator.

\section{1 | Statistical analysis}

The oncologist's evaluation of the eight selected tasks was described by means of median and interquartile range (IQR). The median test was used against the null hypothesis (median $=5$ ) of indecision between no impairment ( 0 ) and maximum severity (10). When the task obtained a median score of motor (sensory) impairment significantly different from the indecision score, it was classified as a task hypothetically able or not to recognize motor (sensory) impairment if higher or lower than 5, while in case of no significant difference from the indecision, it was classified as an uncertain task.

Patients were classified as pathological, or not, according to their strength and sensory loss evaluated by means of TNSc scoring (items strength and vibration sensibility), and they were considered as normal in case of score equal to 0 , or pathological when the score was equal to or greater than 1.

Association between the response to the eight tasks and TNSc evaluations was represented as percentage of pathological patients by each task response and was tested by means of the Cochran-Armitage test for trend, to evaluate if the pathological patient's percentage was increasing by worsening answers. This association was evaluated overall on the entire sample and by received treatment (Platinum drugs and Taxanes). The multiplicity correction according to Hommel was applied. $P$-values were considered statistically significant if lower than 0.05 . Analyses were carried out by means of the statistical software SAS v.9.4 (SAS Institute Inc, Cary, NC).

\section{5 | RESULTS}

The distribution of the scores attributed by oncologists to each daily life maximum limitation ("impossible") allowed for the categorization of the responses into 3 groups: Group 1 included the limitations that the oncologists attributed mainly to motor impairment (item median motor score $=7$, item median sensory score 2-3), Group 2 consisted of limitations mainly attributed to sensory impairment (item median sensory score $=8$, item median motor score $=1-2$ ) and Group 3 included limitations with uncertain motor and sensory impairment (item median sensory score $=4-6$, item median motor score $=5$ ). Table 1 reports the detailed statistical analysis at the basis of the groups stratification which was used thereafter for all analyses.

\section{1 | Correlation between activity limitation and neurological impairment}

As expected based on the enrollment criteria of the original $\mathrm{Cl}$ PeriNoms study that was performed in patients with stable CIPN, ${ }^{12}$ most of the subjects reported some degree of activity limitation. The presence of motor and sensory impairment in subjects who reported that each given task was "impossible", "difficult to be performed" or "easy to be performed" are reported in Table 2. Sensory impairment was generally more frequent than motor impairment in all groups and 
TABLE 2 Percentage of patients with pathological scores at the TNSc, by different answers to questions in the three groups of limitations ( $P$-values are adjusted for multiplicity correction according to Hommel)

\begin{tabular}{|c|c|c|c|c|c|c|c|}
\hline \multirow[b]{2}{*}{ Group } & \multirow[b]{2}{*}{ Questions } & \multirow[b]{2}{*}{ Answers } & \multirow[b]{2}{*}{$N$} & \multicolumn{4}{|c|}{$\begin{array}{l}\text { Percentage of patients with } \\
\text { pathological scores, by answers }\end{array}$} \\
\hline & & & & Motor & $P$-value & Sensory & $P$-value \\
\hline \multirow{4}{*}{$\begin{array}{l}\text { Group 1-limitations attributed mainly to } \\
\text { motor impairment }\end{array}$} & \multirow[t]{3}{*}{ Stand up from a squatting position } & impossible & 37 & 51 & & 78 & \\
\hline & & difficult to be performed & 126 & 25 & 0.2167 & 68 & 0.9265 \\
\hline & & easy to be performed & 105 & 29 & & 76 & \\
\hline & Walking up two flights of stairs & easy to be performed & 142 & 25 & & 75 & \\
\hline \multirow{9}{*}{$\begin{array}{l}\text { Group 2-limitations oncologists attributed } \\
\text { mainly to sensory impairment }\end{array}$} & \multirow[t]{3}{*}{ Handle small objects } & impossible & 19 & 47 & & 84 & \\
\hline & & difficult to be performed & 131 & 34 & 0.0674 & 80 & 0.0148 \\
\hline & & easy to be performed & 123 & 23 & & 63 & \\
\hline & \multirow[t]{3}{*}{ Zip your trousers } & impossible & 9 & 56 & & 100 & \\
\hline & & difficult to be performed & 84 & 42 & 0.0127 & 84 & 0.0015 \\
\hline & & easy to be performed & 177 & 23 & & 65 & \\
\hline & \multirow[t]{3}{*}{ Tie your laces } & impossible & 25 & 48 & & 92 & \\
\hline & & difficult to be performed & 110 & 36 & 0.0109 & 79 & 0.0015 \\
\hline & & easy to be performed & 127 & 20 & & 62 & \\
\hline \multirow{3}{*}{$\begin{array}{l}\text { Group 3-limitations oncologists attributed } \\
\text { both to motor and sensory impairment }\end{array}$} & \multirow[t]{3}{*}{ Stand on one leg } & impossible & 51 & 49 & & 82 & \\
\hline & & difficult to be performed & 111 & 24 & 0.1642 & 71 & 0.9265 \\
\hline & & easy to be performed & 103 & 29 & & 72 & \\
\hline
\end{tabular}

Abbreviation: total neuropathy score-clinical.

for all questions, with altered vibration detection threshold at the TNSc in $73 \%$ of patients (score $1=20 \%$, score $2=27 \%$, score $3=13 \%$, score $4=13 \%$ ), while strength was reduced in $30 \%$ of them (score $1=24 \%$, score $2=5 \%$, score $3=1 \%$ ). In most cases (but not in all the set of questions) a significant trend between severity in subjective activity limitation reported by patients and neurological impairment at the TNSc was present (ie, highest percentage of TNSc pathological features in patients describing a given item as "impossible" to be performed vs "difficult to be performed" or "easy to be performed").

Regarding the subjective perception of drug-induced activity limitation, it is remarkable that in at least $65 \%$ of patients describing the activity as "easy to be performed", they had evidence of some degree of sensory impairment upon neurological examination, while neurological impairment at the TNSc was less evident for strength reduction (20-30\%).

In this population, the percentage of subjects describing at least one of the selected eight daily life activities as "impossible" to be performed, who had at the neurological examination reduced strength, ranged from $43 \%$ to $65 \%$ according to the different items, while this occurred in $76 \%-100 \%$ of cases for abnormal vibration perception (Table 2). Despite the clear predominance of sensory impairment, a combined sensorimotor deficit was always present in each item, although this does not always imply that each patient had combined sensorimotor impairment.

The association between activity limitation and neurological impairment was highly variable among the different questions, and it was related in most cases to both the question and the type of chemotherapy treatment received (Tables 3 and 4). For instance, in Group 1 questions (attributed by oncologists to motor impairment), patients reporting the activity as "impossible" had motor impairment at the TNSc in $67 \%$ of subjects who received taxanes vs $35 \%$ of those who were treated with platinum drugs for the question "Stand up from a squatting position", but subjects were impaired in $71 \%$ of cases for both motor and sensory impairment considering the question "Walking up two flights of stairs". In Group 3 (where oncologists were unable to attribute the limitation to predominant sensory or motor impairment) at the question "Stand on one leg" were associated $73 \%$ of motor and sensory impairments after taxanes therapy, but $27 \%$ vs $86 \%$ for motor or sensory impairment after receiving platinum drugs. In the same group, "Walking on uneven ground" was more frequently associated with motor impairment after taxanes, but rather with sensory impairment after platinum-based chemotherapy. 
TABLE 3 Percentage of patients with pathological scores at the TNSc, by different answers: only Platinum-drug ( $P$-values are adjusted for multiplicity correction according to Hommel)

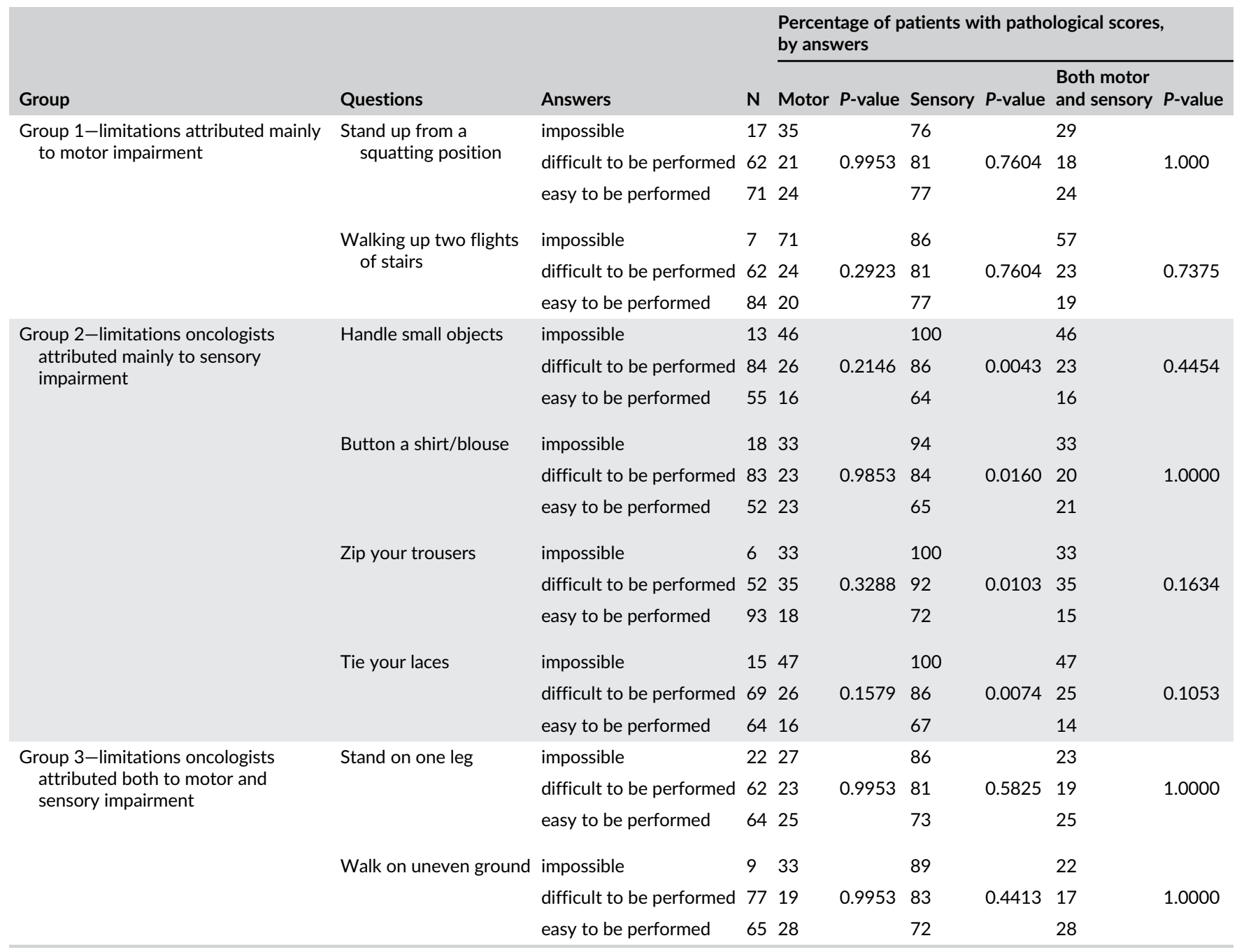

Abbreviation: total neuropathy score-clinical.

It is also remarkable that the percentage of subjects with both sensory and motor impairment at the TNSc had for most items a nearly complete/complete overlap with motor impairment in platinum-treated patients, while this was less evident after taxane treatment.

\subsection{Oncologists interpretation of activity limitation}

Because in daily practice it is crucial that patients report the occurrence of any side effect with as much precision as possible, to the treating physician in order to properly monitor and adjust the treatment, we tested the correlation between subjective perception of activity limitation and oncologists' interpretation of the neurological cause of the impairment. Next, we compared the interpretation with the actual neurological status assessed by an experienced neurologist.

In Group 1, including limitations in standing up from a squatting position and walking up two flights of stairs interpreted by oncologists as likely due to motor impairment, the formal neurological examination confirmed the presence of motor impairment (any grade, in most cases mild) in only $51-65 \%$ of patients belonging to the Cl-PeriNoms cohort who defined that function as "impossible". Remarkably 76-78\% of the patients also had vibration perception impairment (in 32-67\% of them the impairment was grade 3 or 4 in the TNSc( , thus indicating moderate-to-severe impairment). Statistical analysis demonstrated a significant trend only between the difficulty in performing the task and motor impairment, while this trend was not present for sensory impairment (Table 2).

In Group 2, where the limitations referred in handling small objects (eg, coins), buttoning a shirt/blouse, zipping trousers and tie shoes laces were attributed by oncologists to sensory impairment, the percentage of patients in the $\mathrm{Cl}$-PeriNoms cohort with vibration detection impairment was extremely high (ranging from $84 \%$ to $100 \%$ ), with severe sensory impairment occurring in $44 \%-70 \%$, but also some degree of motor impairment occurred in $43 \%-56 \%$ of the patients. Analyzing this group of items, statistical analysis showed a significant trend between the difficulty in performing the task and not only sensory, but also motor impairment (with the only exception of buttoning a shirt/blouse) (Table 2).

In Group 3 (limitation in standing on one leg or walking on uneven ground) strength reduction was observed in $49 \%$ and $50 \%$, respectively; and vibration detection threshold was altered up to $82 \%$ in 
TABLE 4 Percentage of patients with pathological scores at the TNSc, by different answers: only Taxanes ( $P$-values are adjusted for multiplicity correction according to Hommel)

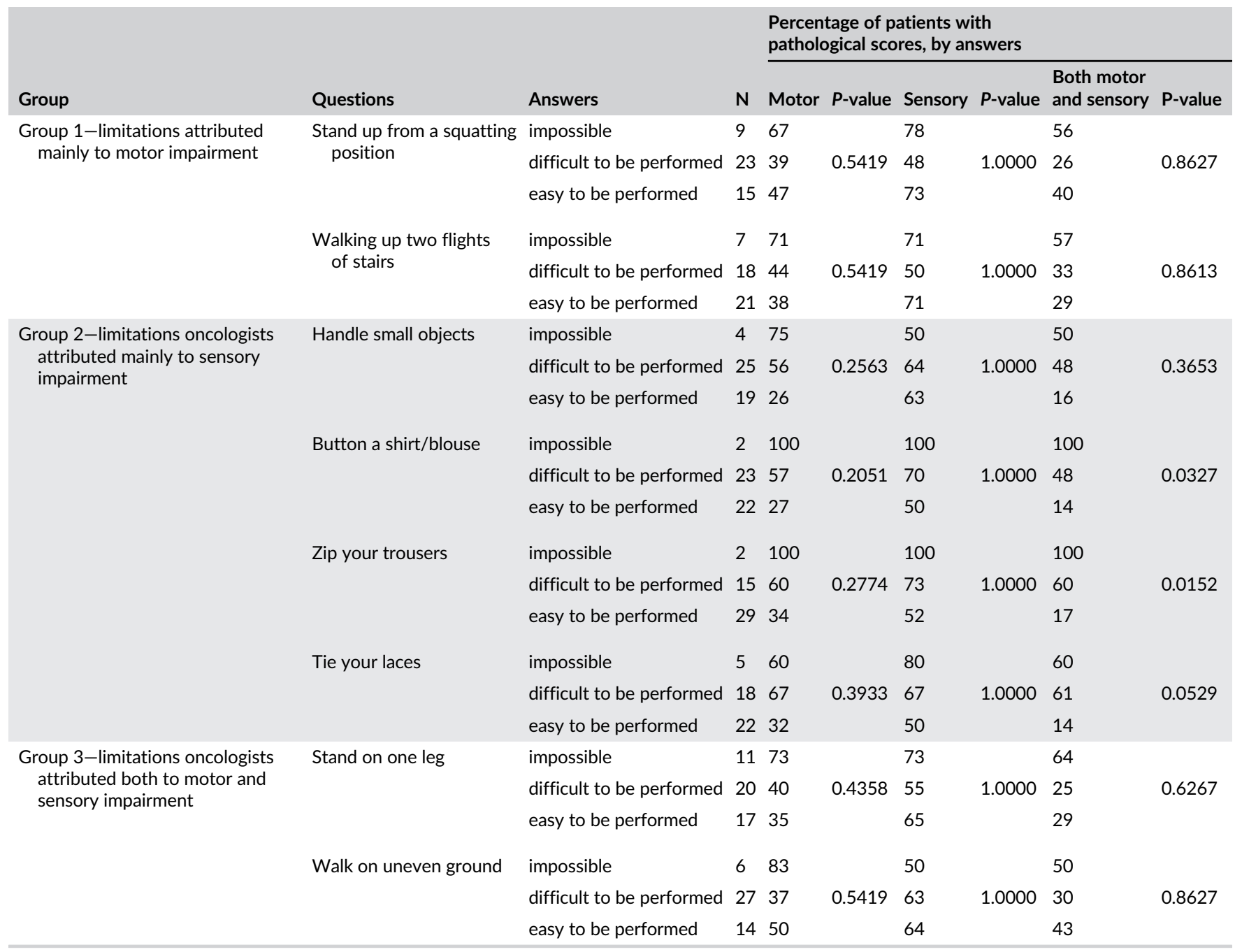

Abbreviation: total neuropathy score-clinical.

both questions (37\% and $36 \%$, respectively with regard to grade $3-4$ impairment) of the $\mathrm{Cl}$-PeriNoms patients unable perform the task. Statistical analysis in this group showed a significant trend between the difficulty in performing the task and motor impairment only for standing on one leg (Table 2).

\section{6 | DISCUSSION}

It is becoming more and more widely accepted that the assessment of CIPN must rely predominantly on subjective perceptions as reported by the affected subjects. The most widely used PROs are based on simple questions referring to common daily activities, and they are intended to be useful for all types of CIPN, although it is well known that different neurotoxic drugs have remarkably diverse neurotoxicity profiles. $^{1,2}$ However, one of the most widely used questionnaires, the QLQ-EORTC CIPN20, after validation analysis based on clinical trials data including more than 1000 patients, failed to show a stable subscale structure, while its use as a simple additive checklist resulted in acceptable validity. ${ }^{13}$ Because this was the largest validation study of this type, it is possible that similar results might be obtained when testing other PRO questionnaires.

This secondary analysis was performed in order to test the criterion validity of each self-reported item selected by neurologists with long-lasting experience in the assessment of CIPN among a list of questions used to create a new, Rasch-built CIPN questionnaire ${ }^{14}$ currently under validation. Since answers to simple questions, such as those used in this study and those forming the basis for PRO instruments, are likely to be influenced by several, convergent events/conditions, possible misinterpretations may occur when a patient reports daily life impairment to the treating oncologist. Therefore, a formal assessment of the relationship among patients' perception of CIPN severity, oncologists' interpretation of patients' report and actual neurological impairment might contribute to a more rationale selection of the optimal assessment to be used in clinical trials. However, this can also have important implications in daily clinical practice providing oncologists more precise understanding of the possible significance of patients' answers.

More reliable information on the real significance of patients' answers can be achieved only through a formal comparison of patients' self-assessment, oncologist's interpretation of their reports 
and a neurological assessment. This complex analysis is not yet available, and it was the core objective of the current secondary analysis.

As a first observation, it should be noted that in our study population of patients with CIPN where we analyzed the presence (and not the severity) of neurological damage, there was a wide representation of both sensory and motor impairment, frequently occurring in the same patient, although from the original $\mathrm{Cl}$-PeriNoms study we know that in our study population motor impairment was less severe than sensory impairment, reflecting the typical CIPN patients. ${ }^{13}$ However, the present analysis indicates that the reported absence of daily life activity limitation is already frequently associated with some degree of neurological impairment, particularly on the sensory side.

It is also remarkable that the interpretation of patients' report provided by the panel of oncologist with high level of attention to CIPN is poorly consistent with the actual neurological impairment, thus raising additional concerns, particularly for the possible implications in daily clinical practice and for decisions on treatment modification.

In order to test if any drug-related effect could be linked to patients' perception and oncologists' interpretation, we compared two subgroups with nearly exclusive sensory impairment due to platinum drugs administration vs sensorimotor damage due to taxanes. The drug-related differences evidenced in our analysis suggest that patients' answers to simple questions should be checked drug-by-drug in order to be more accurate, and this may suggest the need for "drug-specific" questionnaires, not yet available in validated forms. These drug-specific questionnaires, focused on more relevant effects of each drug class, might improve the capacity to detect significant effects of therapeutic intervention in CIPN avoiding the "dilution effect" of non-sensitive or non-relevant questions.

While our previously reported clinical study was performed in a highly selected, fully characterized population, with repeated check of each patients' self-assessment and neurological examination, ${ }^{13}$ and oncologists' opinion were collected in a completely blinded fashion, the present results cannot be directly translated into CIPN assessment during treatment. In fact, our data come from a population of patients with stable CIPN, and thus our results may not totally apply to CIPN development during treatment. In this latter setting, we suspect that patients' answers might be even more prone to misinterpertation, since during chemotherapy, patients may be exposed to a wider range of confounding conditions unrelated to CIPN, but that limit daily activities and overlap CIPN effects (eg, infections, anemia, fatigue, depression and "chemofog").

In conclusion, we demonstrated that the interpretation of patients' report provided by the panel of oncologists is poorly consistent with the actual neurological impairment and that activity limitations capture more than simple impairments and reflect a broader impact than impairment measures. These observations form a critical basis for further research on the core set of outcome measures needed for future CIPN trials and at the same time raise concern on the current use of the available PROs alone as main endpoints in CIPN trials.

\section{ORCID}

Guido Cavaletti (D) https://orcid.org/0000-0003-4128-2406

Paola Alberti (D) https://orcid.org/0000-0001-6106-6183

Chiara Briani (D) https://orcid.org/0000-0001-8035-0200

\section{REFERENCES}

1. Grisold W, Cavaletti G, Windebank AJ. Peripheral neuropathies from chemotherapeutics and targeted agents: diagnosis, treatment, and prevention. Neuro Oncol. 2012;14(suppl 4):iv45-iv54.

2. Cavaletti G, Marmiroli P. Chemotherapy-induced peripheral neurotoxicity. Curr Opin Neurol. 2015;28:500-507.

3. Alberti P, Rossi E, Cornblath DR, et al. Physician-assessed and patientreported outcome measures in chemotherapy-induced sensory peripheral neurotoxicity: two sides of the same coin. Ann Oncol. 2014;25:257-264.

4. Kolb N, Burns T. Clinical research in chemotherapy-induced peripheral neuropathy: how, what, and when. Neurology. 2018;91:379-380.

5. Gewandter JS, Brell J, Cavaletti G, et al. Trial designs for chemotherapy-induced peripheral neuropathy prevention: ACTTION recommendations. Neurology. 2018;91:403-413.

6. Frigeni $B$, Piatti M, Lanzani F, et al. Chemotherapy-induced peripheral neurotoxicity can be misdiagnosed by the National Cancer Institute Common Toxicity scale. J Peripher Nerv Syst. 2011;16:228-236.

7. Haryani H, Fetzer SJ, Wu CL, Hsu YY. Chemotherapy-induced peripheral neuropathy assessment tools: a systematic review. Oncol Nurs Forum. 2017;44:E111-E123.

8. McCrary JM, Goldstein D, Boyle F, et al. Optimal clinical assessment strategies for chemotherapy-induced peripheral neuropathy (CIPN): a systematic review and Delphi survey. Support Care Cancer. 2017;25: 3485-3493.

9. Gewandter JS, Burke L, Cavaletti G, et al. Content validity of symptom-based measures for diabetic, chemotherapy, and HIV peripheral neuropathy. Muscle Nerve. 2017;55:366-372.

10. Gewandter JS, Freeman R, Kitt RA, et al. Chemotherapy-induced peripheral neuropathy clinical trials: review and recommendations. Neurology. 2017;89:859-869.

11. Gegechkori N, Haines L, Lin JJ. Long-term and latent side effects of specific cancer types. Med Clin North Am. 2017;101:1053-1073.

12. Cavaletti G, Cornblath DR, Merkies ISJ, et al. The chemotherapyinduced peripheral neuropathy outcome measures standardization study: from consensus to the first validity and reliability findings. Ann Oncol. 2013;24:454-462.

13. Kieffer JM, Postma TJ, van de Poll-Franse L, et al. Evaluation of the psychometric properties of the EORTC chemotherapy-induced peripheral neuropathy questionnaire (QLQ-CIPN20). Qual Life Res. 2017;26:2999-3010.

14. Binda D, Vanhoutte EK, Cavaletti G, et al. Rasch-built Overall Disability Scale for patients with chemotherapy-induced peripheral neuropathy (CIPN-R-ODS). Eur J Cancer. 2013;49:2910-2918.

How to cite this article: Cavaletti G, Cornblath DR, Merkies ISJ, et al. Patients' and physicians' interpretation of chemotherapy-induced peripheral neurotoxicity. J Peripher Nerv Syst. 2019;24:111-119. https://doi.org/10.1111/jns.12306 


\section{APPENDIX: CI-PERINOMS GROUP}

\begin{tabular}{|c|c|c|}
\hline Name & Location & Contribution \\
\hline Guido Cavaletti, MD & University of Milano-Bicocca, Monza & $\begin{array}{l}\text { Study concepts, Study design, Data analysis and } \\
\text { interpretation, Manuscript preparation, Manuscript } \\
\text { editing, Manuscript review. }\end{array}$ \\
\hline Ingemar S.J. Merkies, MD, PhD & St. Elisabeth Hospital, Willemstad & $\begin{array}{l}\text { Study concepts, Study design, Manuscript editing, } \\
\text { Manuscript review. }\end{array}$ \\
\hline Emanela Rossi, MSc, PhD & University of Milano-Bicocca, Monza & $\begin{array}{l}\text { Data analysis and interpretation, Statistical analysis, } \\
\text { Manuscript preparation, Manuscript editing, } \\
\text { Manuscript review. }\end{array}$ \\
\hline Paola Alberti, MD, PhD(c) & University of Milano-Bicocca, Monza & $\begin{array}{l}\text { Study concepts, Study design, Data acquisition, Data } \\
\text { analysis and interpretation, Manuscript preparation, } \\
\text { Manuscript editing, Manuscript review. }\end{array}$ \\
\hline Chiara Briani, MD & University of Padova, Padova & Data acquisition, Manuscript editing, Manuscript review. \\
\hline Roser Velasco, MD, PhD & University Hospital of Patras, Patras & Data acquisition, Manuscript editing, Manuscript review. \\
\hline Haralabos P. Kalofonos, MD, PhD & University Hospital of Patras, Patras & Data acquisition, Manuscript editing, Manuscript review. \\
\hline Dimitri Psimaras, MD & Hôpital de la Pitié-Salpêtrière, AP-HP, Paris & Data acquisition, Manuscript editing, Manuscript review. \\
\hline Damien Ricard, MD & Service de Santé des Armées, Clamart & Data acquisition, Manuscript editing, Manuscript review. \\
\hline Andrea Pace, MD & Regina Elena National Cancer Institute, Rome & Data acquisition, Manuscript editing, Manuscript review. \\
\hline Catharina G. Faber, MD PhD & Maastricht University Medical Center, Maastricht & Data acquisition, Manuscript editing, Manuscript review. \\
\hline Roy I Lalisang, MD, PhD & Maastricht University Medical Center, Maastricht & Data acquisition, Manuscript editing, Manuscript review. \\
\hline Dieta Brandsma, MD & Netherlands Cancer Institute, Amsterdam & Data acquisition, Manuscript editing, Manuscript review. \\
\hline Luca Padua, MD & Cattolica University, Rome & Data acquisition, Manuscript editing, Manuscript review. \\
\hline Susan G. Dorsey, PhD, RN, FAAN & $\begin{array}{l}\text { University of Maryland School of Nursing and the } \\
\text { Marlene and Stewart Greenebaum Cancer Center, } \\
\text { Baltimore }\end{array}$ & Data acquisition, Manuscript editing, Manuscript review. \\
\hline Marta Penas-Prado, MD & The UT MD Anderson Cancer Center, Houston & Data acquisition, Manuscript editing, Manuscript review. \\
\hline Maria G. Valsecchi MG, MSc & University of Milano-Bicocca, Monza & $\begin{array}{l}\text { Data analysis and interpretation, Statistical analysis, } \\
\text { Manuscript preparation, Manuscript editing, } \\
\text { Manuscript review. }\end{array}$ \\
\hline Barbara Frigeni, MD & Papa Giovanni XXIII Hospital, Bergamo & Data acquisition. Manuscript revision and approval. \\
\hline Francesca Lanzani, MD & Niguarda Hospital, Milano & Data acquisition. Manuscript revision and approval. \\
\hline Laura Mattavelli, MD & Vimercate Hospital, Vimercate & Data acquisition. Manuscript revision and approval. \\
\hline Maria Luisa Piatti, MD & San Gerardo Hospital, Monza & Data acquisition. Manuscript revision and approval. \\
\hline Davide Binda, MD & Valduce Hospital, Como & Data acquisition. Manuscript revision and approval. \\
\hline Paolo Bidoli, MD & San Gerardo Hospital, Monza & Data acquisition. Manuscript revision and approval. \\
\hline Marina Cazzaniga, MD & San Gerardo Hospital, Monza & Data acquisition. Manuscript revision and approval. \\
\hline Diego Cortinovis, MD & San Gerardo Hospital, Monza & Data acquisition. Manuscript revision and approval. \\
\hline Edvina Galiè, MD & IRCCS Regina Elena National Cancer Institute & Data acquisition. Manuscript revision and approval. \\
\hline Marta Campagnolo, MD & University of Padova, Padova & Data acquisition. Manuscript revision and approval. \\
\hline Andrea Salvalaggio, MD & University of Padova, Padova & Data acquisition. Manuscript revision and approval. \\
\hline
\end{tabular}




\begin{tabular}{|c|c|c|}
\hline Name & Location & Contribution \\
\hline Marta Ruiz, MD & University of Padova, Padova & Data acquisition. Manuscript revision and approval. \\
\hline Els K Vanhoutte, MD, PhD & Maastricht University Medical Centre, Maastricht & Data acquisition. Manuscript revision and approval. \\
\hline W Boogerd, MD & Netherlands Cancer Institute, Amsterdam & Data acquisition. Manuscript revision and approval. \\
\hline J Hense, MD & University of Essen, Germany & Data acquisition. Manuscript revision and approval. \\
\hline Robin Grant, MD & Western General Hospital, Edinburgh & Data acquisition. Manuscript revision and approval. \\
\hline Dawn Storey, MD & Western General Hospital, Edinburgh & Data acquisition. Manuscript revision and approval. \\
\hline Lizia Reni, MD & IRCCS Policlinico San Martino, Genova & Data acquisition. Manuscript revision and approval. \\
\hline Chiara Demichelis, MD & DINOGMI, University of Genova, Genova & Data acquisition. Manuscript revision and approval. \\
\hline Annamaria Pessino, MD & IRCCS Policlinico San Martino, Genova & Data acquisition. Manuscript revision and approval. \\
\hline Giuseppe Granata, MD & Cattolica University, Rome & Data acquisition. Manuscript revision and approval. \\
\hline Massimo Leandri, MD & DINOGMI, University of Genova, Genova & Data acquisition. Manuscript revision and approval. \\
\hline I Ghigliotti, MD & University of Genova, Genova & Data acquisition. Manuscript revision and approval. \\
\hline Rosaria Plasmati, MD & Bellaria Hospital, Bologna & Data acquisition. Manuscript revision and approval. \\
\hline Francesca Pastorelli, MD & Bellaria Hospital, Bologna & Data acquisition. Manuscript revision and approval. \\
\hline JJ Heimans, MD & Amsterdam UMC, Amsterdam & Data acquisition. Manuscript revision and approval. \\
\hline Marijke Eurelings, MD & Spaarne Hospital, Hoofddorp & Data acquisition. Manuscript revision and approval. \\
\hline Ron J Meijer, MD & Spaarne Hospital, Hoofddorp & Data acquisition. Manuscript revision and approval. \\
\hline Elisabeth Lindeck Pozza, MD & $\begin{array}{l}\text { Ludwig Boltzmann Institute for Experimental und } \\
\text { Clinical Traumatology, Vienna }\end{array}$ & Data acquisition. Manuscript revision and approval. \\
\hline Antonio Toscano, MD & University of Messina, Messina & Data acquisition. Manuscript revision and approval. \\
\hline Luca Gentile, MD & University of Messina, Messina & Data acquisition. Manuscript revision and approval. \\
\hline Mariacarmela Santarpia, MD & University of Messina, Messina & Data acquisition. Manuscript revision and approval. \\
\hline C Dominguez Gonzalez, MD & The UT MD Anderson Cancer Center, Houston & Data acquisition. Manuscript revision and approval. \\
\hline
\end{tabular}

